\title{
NUMERICAL STUDY OF THE EFFECT OF WING POSITION ON THE DYNAMIC MOTION CHARACTERISTICS OF AN UNDERWATER GLIDER
}

\author{
Xiangcheng Wu \\ Pengyao Yu* \\ Guangzhao Li \\ Fengkun Li \\ Dalian Maritime University, China \\ *Corresponding author: yupengyao@dlmu.edu.cn (P. Yu)
}

\begin{abstract}
Underwater gliders are winged, autonomous underwater vehicles that are broadly applied in physical and biological oceanography. The position of the wing has an important effect on the movement performance of the underwater glider. In this paper, the dynamic motion of a series of underwater glider models with different longitudinal wing positions are simulated, which provides guidance for the design of underwater gliders. The results show that when the net buoyancy is constant, the wing position affects the gliding angle, but does not affect the relationship between the gliding angle and the gliding speed. In addition, the farther the wing position of the glider is from the buoyancy centre, the longer it takes for the attitude of a glider to change, whether the wing is in front of, or behind, the buoyancy centre.
\end{abstract}

Keywords: underwater glider, motion simulation, wing position

\section{INTRODUCTION}

An underwater glider is a special type of autonomous underwater vehicle which is controlled by adjusting its buoyancy. Since the idea for an underwater glider was put forward by Stommel [1] in 1989, it has attracted wide attention. For the characteristics of low energy consumption, low cost and long range, several typical underwater gliders have been developed and broadly applied in physical and biological oceanography, such as Slocum [2], Spray [3], Seaglider [4], Petrel [5] and Seawing [6].

Underwater gliders can change direction by controlling their centre of gravity and moving in the horizontal plane by the hydrodynamic force exerted on the wings. As a result, underwater gliders follow a saw tooth motion in the vertical plane [7]. Therefore, the wings greatly affect the dynamic motion characteristics of underwater gliders by influencing the hydrodynamic characteristics. Shankar [8] studied the impact of the variation of wing position on the hydrodynamic characteristics of an underwater glider with NACA0012 wings by computational fluid dynamics (CFD) methodology.
The study brings out that the wing position at the farther aft improves the lift-drag ratio and stability in the longitudinal motion of the glider but the increase of the lift-drag ratio is small across all angles of attack, with a slight increase at higher angles $\left( \pm 8^{\circ}\right)$. Javaid [9] studied the effect of wing form on the hydrodynamic characteristics of an underwater glider by experimental and numerical methods. The results show that a rectangular winged glider has higher lift force and drag force than the tapered wing glider due to a larger wetted area. The author also studied the effect on the dynamic stability by numerical methods. The results show that the tapered wing glider has higher linear velocity while the rectangular wing glider has a smaller spiral turning radius [10]. Zhang [11] developed a prototype of a gliding robotic fish with two types of wings. The wings had the same wingspan but different aspect ratios. By analysing the motion performance of the gliding robotic fish with different wings during steady gliding, the author came to the conclusion that the larger wings result in shallower gliding paths, but a slower gliding speed compared to the smaller wings. Liu [12] designed an orthogonal test to study the impact of wing parameters on the movement efficiency and 
stability of a hybrid underwater glider. The results show that the chord length has the most remarkable effect on the movement efficacy while the axial position has a negligible effect on the movement efficacy. The sweep angle has the most significant impact on the stability of the underwater glider. Fan [13] studied the impact of geometric parameters on the steady wings-level flight of a generic glider shape. The conclusions included the fact that higher speeds can be attained using smaller wingspans and higher wing aspect ratios for a glider with fixed mass and buoyancy capacity. A higher lift-drag ratio can be attained by increasing the wingspan ratio at a given gliding angle speed and, the father aft the wing is located, the more stable the glider's longitudinal dynamics becomes, which is due, in part, to the increased pitch damping.

In Graver [14] and Bhatta [15], dynamic models of underwater gliders were established and corresponding motion simulation analysis was conducted. In Leonard [16] and Bhatta [17], the nonlinear gliding stability was analysed and stabilising control methods for gliders were discussed. In Isa $[18,19]$ and Noh [20], a kinetic model for the underwater glider designed by the University of Science, Malaysia, was established. Fan [21] presented a multibody dynamic model for an underwater glider which was operating in an unsteady non-uniform flow field.

The effect of wing position on the hydrodynamic characteristics of underwater gliders has been studied by the CFD method but these studies do not directly show the effect of wing position on motion characteristics. In this paper, the effect of wing position on the dynamic motion characteristics of an underwater glider is studied by simulating three typical motion states: the motion of steady gliding, the motion after receiving a small disturbance, and the motion after adjusting the position of the movable block.

The paper is organised as follows. Section 2 derives the dynamic model for underwater gliders. Section 3 describes the models constructed in this paper and calculates the hydrodynamic parameters needed by the dynamic model. Section 4 simulates several motion states of different models and analyses the effect of wing position. Section 5 summarises the main conclusions.

\section{DYNAMIC MODEL}

\section{REFERENCE FRAMES}

In this paper, the inertial frame $E-\xi \eta \zeta$, the body frame $O-X Y Z$ and the flow frame $V-V_{1} V_{2} V_{3}$ are adopted to describe the motion of the glider and are shown in Fig. 1 [22].

The inertial frame $E-\xi \eta \zeta$ is fixed in the inertial space and the coordinate axis $E-\zeta$ points to the direction of gravity. The origin of body frame $O-X Y Z$ is fixed at the buoyancy centre of the glider. The $O-Y$ axis coincides with the longitudinal axis of the glider and the $O-Y$ axis lies in the wing plane, pointing to the right. The position $\boldsymbol{b}$ and the attitude $\boldsymbol{\Omega}$ of the underwater glider in the inertial frame and the linear velocity $v$ and angular velocity $\boldsymbol{\omega}$ of the glider in the body frame are defined as:

$$
\boldsymbol{b}=\left\{\begin{array}{c}
\xi_{B} \\
\eta_{B} \\
\zeta_{B}
\end{array}\right\}, \boldsymbol{\Omega}=\left\{\begin{array}{c}
\varphi \\
\theta \\
\psi
\end{array}\right\}, \boldsymbol{v}=\left\{\begin{array}{c}
u \\
v \\
w
\end{array}\right\}, \boldsymbol{\omega}=\left\{\begin{array}{c}
p \\
q \\
r
\end{array}\right\},
$$

The flow frame is defined relative to the body frame. First, the attack angle $\alpha$ and the slip angle $\beta$ are defined as:

$$
\alpha=\tan ^{-1}\left(\frac{w}{u}\right), \beta=\tan ^{-1}\left(\frac{v}{\|v\|}\right)
$$

The body frame is then rotated around the $O-Y$ axis by the angle $-\alpha$ and around the new $O-Z$ axis by the angle $\beta$. As a result, the body frame is rotated to a new position which is defined as the flow frame $V-V_{1} V_{2} V_{3}$, as shown in Fig. 1.

The underwater glider is regarded as a system of mass blocks in this paper. The components of the system are shown in Table 1. It should be noted that all the positions are given by the vectors from the buoyancy centre to the respective masses in the body frame. As shown in Fig. 2, the centre of the movable block is located at position $r_{p x}$ along the $O-X$ axis with eccentric offset $\boldsymbol{R}_{p}$, and is rotated with an angle $\gamma$ around the $O-X$ axis.
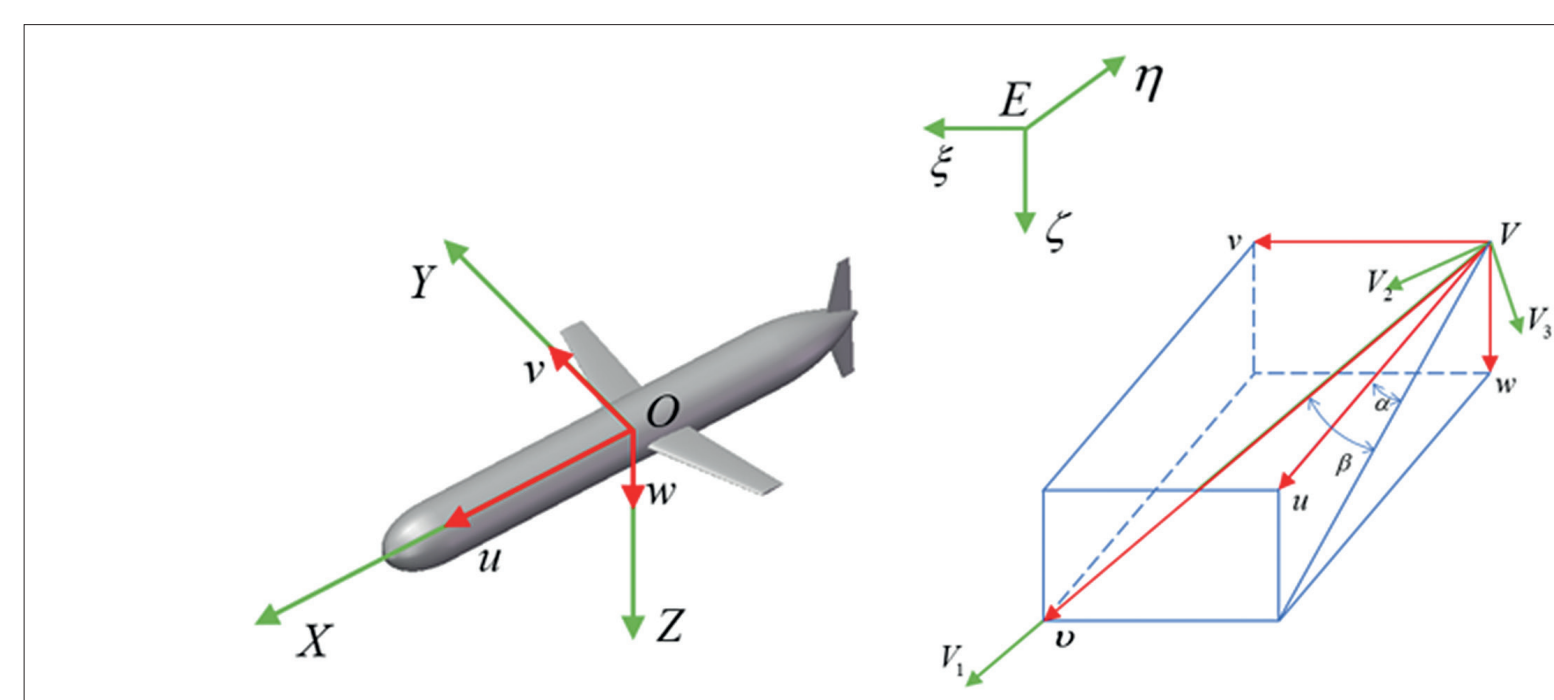

Fig. 1. Reference frames 
Tab. 1. The components of the underwater glider system

\begin{tabular}{|c|c|c|}
\hline & Mass & Position \\
\hline Movable block & Stationary mass $m_{p}$ & Variable position $r_{p}$ \\
\hline Net buoyancy & Adjustable mass $m_{b}$ & Constant position $r_{b}$ \\
\hline $\begin{array}{c}\text { All other fixed } \\
\text { structures }\end{array}$ & Stationary mass $m_{h}$ & Constant position $r_{h}$ \\
\hline
\end{tabular}

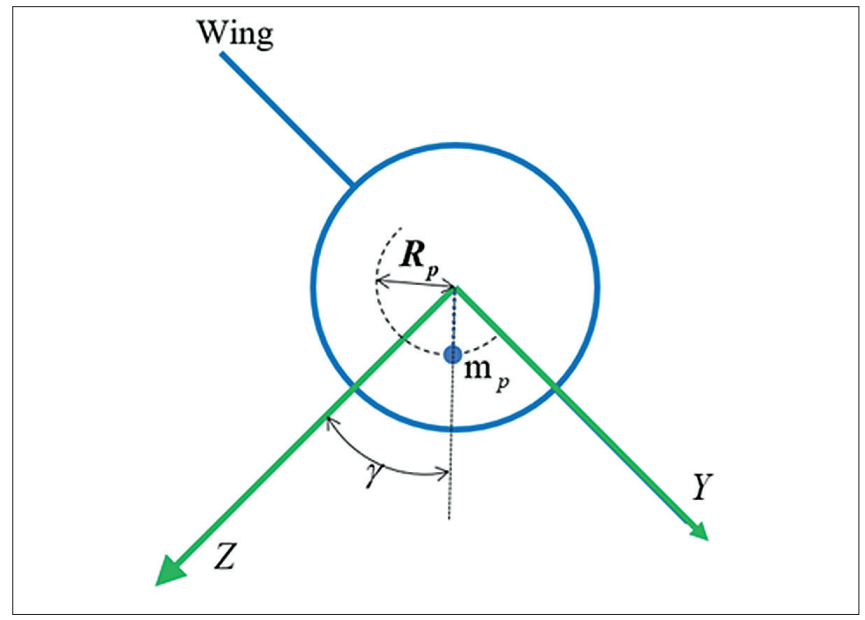

Fig. 2. Mechanisms of turning spiralling motion

\section{KINEMATICS}

According to the reference frames, the inertial velocity and the attitude kinematics of the glider system are defined in [23].

$$
\begin{aligned}
& \dot{b}=R_{E B} v \\
& \dot{R}_{E B}=R_{E B} \hat{\omega}
\end{aligned}
$$

$\boldsymbol{R}_{E B}$ is a rotational transformed matrix from the body frame to the inertial frame. The operator ' $\because$ ' maps a vector to a $3 \times 3$ skewsymmetric matrix, which satisfies $\hat{\boldsymbol{a}} \boldsymbol{c}=\boldsymbol{a} \times \boldsymbol{c}$ for vectors $\boldsymbol{a}$ and $\boldsymbol{c}$.

The attitude of the glider in the inertial frame can be described by the Euler angle $\Omega$, including the roll angle $\varphi$, the pitch angle $\theta$, and the yaw angle $\psi$. The relationship between the Euler angle rates and the angular velocity of the glider, with respect to the body frame, can be expressed as:

$$
\dot{\Omega}_{E B}=R_{\Omega B} \omega
$$

Transform matrices $\boldsymbol{R}_{E B}$ and $\boldsymbol{R}_{\Omega B}$ have similar properties to $\boldsymbol{R}_{E B}^{-1}=\boldsymbol{R}_{E B}^{T}$ and $\boldsymbol{R}_{\Omega B}^{-1}=\boldsymbol{R}_{\Omega B}^{T}$. Using the simplified notation $\mathrm{c} \cdot=\cos (\cdot), \mathrm{s} \cdot=\sin (\cdot), \mathrm{t} \cdot=\tan (\cdot), \boldsymbol{R}_{E B}$ and $\boldsymbol{R}_{\Omega B}$ are expressed in the form given in [24].

$$
\begin{gathered}
\boldsymbol{R}_{E B}=\left\{\begin{array}{ccc}
c \theta c \psi & s \varphi s \theta c \psi-c \varphi s \psi & c \varphi s \theta c \psi-s \varphi s \psi \\
c \theta s \psi & s \varphi s \theta s \psi-c \varphi c \psi & c \varphi s \theta s \psi-s \varphi c \psi \\
-s \theta & s \varphi c \theta & c \varphi c \theta
\end{array}\right\}, \\
\boldsymbol{R}_{\Omega B}=\left\{\begin{array}{ccc}
1 & s \varphi t \theta & c \varphi t \theta \\
0 & c \varphi & -c \varphi \\
0 & \frac{s \varphi}{c \theta} & \frac{c \varphi}{c \theta}
\end{array}\right\}
\end{gathered}
$$

\section{DYNAMICS}

The gravity of the glider $\boldsymbol{G}$ and the buoyancy of the glider $\boldsymbol{B}$ can be expressed as:

$$
\begin{aligned}
& \boldsymbol{G}=\left(m_{p}+m_{h}+m_{b}\right) g \boldsymbol{k} \\
& \boldsymbol{B}=-\left(m_{p}+m_{h}\right) g \boldsymbol{k}
\end{aligned}
$$

where $\boldsymbol{k}$ is the unit vector of the $E-\zeta$ axis. The net weight of the gilder system can be described as:

$$
\boldsymbol{W}=\boldsymbol{G}+\boldsymbol{B}=m_{b} g \boldsymbol{k}
$$

$m_{b}=0$ when the glider is suspended, therefore the glider would tend to sink when $m_{b}$ is greater than zero but rise when $m_{b}$ is less than zero.

If $p$ represents the translational momentum of the glider system then $\pi$ represents the angular momentum of the glider system about the inertial frame. According to the momentum theorem, we know that

$$
\begin{gathered}
\dot{p}=G+B+f_{\text {ext }} \\
\dot{\pi}=b_{G} \times G+b \times B+b \times f_{\text {ext }}+\tau_{\text {ext }}
\end{gathered}
$$

where $\boldsymbol{b}_{G}$ is the position vectors of the centre of gravity in the inertial frame. $f_{e x t}$ and $\tau_{e x t}$ represent the external force and external moment of the glider system in the inertial frame, respectively. In this paper, only viscous hydrodynamic components are expressed as external forces and moments in the momentum equations.

$\boldsymbol{P}$ and $\boldsymbol{\Pi}$ are defined as the expression of $\boldsymbol{p}$ and $\boldsymbol{\pi}$ in the body frame, so the transformation equations are:

$$
\begin{gathered}
p=R_{E B} P \\
\pi=R_{E B} \Pi+b \times p
\end{gathered}
$$

By differentiating Eq. (9) with respect to time, we get the following equations:

$$
\begin{gathered}
\dot{p}=R_{E B}(\dot{P}+\hat{\omega} P) \\
\dot{\pi}=R_{E B}(\dot{\Pi}+\hat{\omega} \Pi)+R_{E B} v \times p+b \times \dot{p}
\end{gathered}
$$

Substituting Eq. (8) into Eq. (10) will give

$$
\begin{gathered}
\dot{\boldsymbol{P}}=\boldsymbol{P} \times \boldsymbol{\omega}+\boldsymbol{R}_{E B}^{T}(\boldsymbol{G}+\boldsymbol{B})+\boldsymbol{F} \\
\dot{\boldsymbol{\Pi}}=\boldsymbol{\Pi} \times \boldsymbol{\omega}+\boldsymbol{P} \times \boldsymbol{v}+\boldsymbol{r}_{G} \times \boldsymbol{R}_{E B}^{T} \boldsymbol{G}+\boldsymbol{T}
\end{gathered}
$$

where $\boldsymbol{r}_{G}$ is the position vector of the gravity centre in the body frame, $\boldsymbol{F}=\boldsymbol{R}_{E B}^{T} f_{e x t}$ represents viscous hydrodynamic force in the body frame, and $\boldsymbol{T}=\boldsymbol{R}_{E B}^{T} \boldsymbol{\tau}_{\text {ext }}$ represents viscous hydrodynamic moment in the body frame. 
The momentum of the glider system in the body frame can be expressed in the following equations:

$$
\left\{\begin{array}{l}
P \\
\Pi
\end{array}\right\}=M\left\{\begin{array}{c}
v \\
\omega
\end{array}\right\}
$$

where $\boldsymbol{M}$ is the generalised inertia matrix of the glider system.

To find the equations for $\boldsymbol{M}$, we need to derive the total kinetic energy of the glider-fluid system. The kinetic energy of the movable block is

$$
\boldsymbol{T}_{\boldsymbol{p}}=\frac{1}{2}\left[\begin{array}{c}
\boldsymbol{v} \\
\boldsymbol{\omega}
\end{array}\right]^{T}\left[\begin{array}{cc}
m_{p} \boldsymbol{I} & -m_{p} \hat{\boldsymbol{r}}_{\boldsymbol{p}} \\
m_{p} \hat{\boldsymbol{r}}_{\boldsymbol{p}} & \boldsymbol{R}_{x}^{T}(\gamma) \boldsymbol{I}_{p}^{0} \boldsymbol{R}_{x}(\gamma)-m_{p} \hat{\boldsymbol{r}}_{\boldsymbol{p}} \hat{\boldsymbol{r}}_{p}
\end{array}\right]\left[\begin{array}{c}
\boldsymbol{v} \\
\boldsymbol{\omega}
\end{array}\right]
$$

$\boldsymbol{I}$ is the $3 \times 3$ identity matrix. $\boldsymbol{I}_{p}^{0}$ represents the principal inertia matrix of the movable block, computed in the stationary state with $\gamma=0 . \boldsymbol{R}_{x}(\gamma)$ is a rotation matrix for the inertia matrix of the movable block and its expression is:

$$
\boldsymbol{R}_{x}(\gamma)=\left\{\begin{array}{ccc}
1 & 1 & 0 \\
0 & c \gamma & -s \gamma \\
0 & s \gamma & c \gamma
\end{array}\right\}
$$

The kinetic energy of the net buoyancy and the fixed structure of the glider are

$$
\begin{aligned}
& \boldsymbol{T}_{\boldsymbol{b}}=\frac{1}{2}\left[\begin{array}{l}
\boldsymbol{v} \\
\boldsymbol{\omega}
\end{array}\right]^{T}\left[\begin{array}{cc}
m_{b} \boldsymbol{I} & -m_{b} \hat{\boldsymbol{r}}_{\boldsymbol{b}} \\
m_{b} \hat{\boldsymbol{r}}_{\boldsymbol{b}} & -m_{b} \hat{\boldsymbol{r}}_{\boldsymbol{b}} \hat{\boldsymbol{r}}_{\boldsymbol{b}}
\end{array}\right]\left[\begin{array}{l}
\boldsymbol{v} \\
\boldsymbol{\omega}
\end{array}\right] \\
& \boldsymbol{T}_{\boldsymbol{h}}=\frac{1}{2}\left[\begin{array}{l}
\boldsymbol{v} \\
\boldsymbol{\omega}
\end{array}\right]^{T}\left[\begin{array}{cc}
m_{h} \boldsymbol{I} & -m_{h} \hat{\boldsymbol{r}}_{\boldsymbol{h}} \\
m_{h} \hat{\boldsymbol{r}}_{\boldsymbol{h}} & \boldsymbol{I}_{\boldsymbol{h}}-m_{h} \hat{\boldsymbol{r}}_{\boldsymbol{h}} \hat{\boldsymbol{r}}_{\boldsymbol{h}}
\end{array}\right]\left[\begin{array}{l}
\boldsymbol{v} \\
\boldsymbol{\omega}
\end{array}\right]
\end{aligned}
$$

When the glider accelerates in the flow, the surrounding fluid would be affected and accelerated. The kinetic energy of the fluid is

$$
\boldsymbol{T}_{f}=\frac{1}{2}\left[\begin{array}{c}
\boldsymbol{v} \\
\boldsymbol{\omega}
\end{array}\right]^{T}\left[\begin{array}{ll}
\boldsymbol{M}_{f} & \boldsymbol{C}_{f} \\
\boldsymbol{C}_{f}^{T} & \boldsymbol{J}_{f}
\end{array}\right]\left[\begin{array}{c}
\boldsymbol{v} \\
\boldsymbol{\omega}
\end{array}\right]
$$

where, $\boldsymbol{M}_{f}, \boldsymbol{J}_{f}$ and $\boldsymbol{C}_{f}$ are added mass terms, added inertia terms and added coupling terms, respectively.

The total kinetic energy of the glider-fluid system is then

$$
\boldsymbol{T}=\boldsymbol{T}_{p}+\boldsymbol{T}_{\boldsymbol{b}}+\boldsymbol{T}_{\boldsymbol{h}}+\boldsymbol{T}_{\boldsymbol{f}}=\frac{1}{2}\left[\begin{array}{c}
\boldsymbol{v} \\
\boldsymbol{\omega}
\end{array}\right]^{T} \boldsymbol{M}\left[\begin{array}{l}
\boldsymbol{v} \\
\boldsymbol{\omega}
\end{array}\right]
$$

The generalised inertia matrix is

$$
\begin{aligned}
& \boldsymbol{M}=\left\{\begin{array}{c}
\boldsymbol{M}_{f}+\left(m_{p}+m_{b}+m_{h}\right) \boldsymbol{I} \\
\boldsymbol{C}_{f}^{T}+m_{p} \hat{\boldsymbol{r}}_{\boldsymbol{p}}+m_{b} \hat{\boldsymbol{r}}_{\boldsymbol{b}}+m_{h} \hat{\boldsymbol{r}}_{\boldsymbol{h}}
\end{array}\right. \\
& \boldsymbol{C}_{f}-m_{p} \hat{\boldsymbol{r}}_{p}-m_{b} \hat{\boldsymbol{r}}_{\boldsymbol{b}}-m_{h} \hat{\boldsymbol{r}}_{h} \\
& \boldsymbol{J}_{f}+\boldsymbol{I}_{\boldsymbol{h}}+\boldsymbol{R}_{x}^{T}(\gamma) \boldsymbol{I}_{p}^{0} \boldsymbol{R}_{x}(\gamma)-m_{p} \hat{\boldsymbol{r}}_{\boldsymbol{p}} \hat{\boldsymbol{r}}_{\boldsymbol{p}}-m_{b} \hat{\boldsymbol{r}}_{\boldsymbol{b}} \hat{\boldsymbol{r}}_{\boldsymbol{b}}-m_{h} \hat{\boldsymbol{r}}_{\boldsymbol{h}} \hat{\boldsymbol{r}}_{\boldsymbol{h}}
\end{aligned}
$$

Finally, by differentiating Eq. (12) with respect to time, we get the dynamic model to be:

$$
\left\{\begin{array}{c}
\dot{v} \\
\dot{\boldsymbol{\omega}}
\end{array}\right\}=M^{-1}\left\{\left[\begin{array}{c}
\dot{\boldsymbol{P}} \\
\dot{\boldsymbol{M}}
\end{array}\right]-\dot{\boldsymbol{M}}\left[\begin{array}{c}
v \\
\omega
\end{array}\right]\right\}
$$

\section{MODELS AND HYDRODYNAMIC COEFFICIENTS}

\section{MODELS}

Six underwater glider models were designed with different wing positions. The standard NACA0012 section was adopted for the wings, and carbon fibre material, with a density of $2000 \mathrm{~kg} / \mathrm{m}^{3}$, was selected. Some geometric dimensions of gliders are shown in Fig. 3. The distance between the wing root and the nose of the models is listed in Table 2. In addition, as the position of the wing changes, the position of the buoyancy centre also changes. Therefore, the internal structure is adjusted to ensure that the gravity centre of the glider system is directly below the buoyancy centre in the body frame $O-X Y Z$ when the movable block is in its central position. This means that $r_{p}, r_{b}$ and $r_{h}$ have the same values when the movable block is in its central position in the six models. The distance between the buoyancy centre and the

\begin{tabular}{|c|c|c|c|c|c|c|}
\hline$\frac{\infty}{\tilde{J}}$ & $\begin{array}{l}\vec{n} \\
\frac{a}{\tilde{J}} \\
\frac{0}{\Sigma}\end{array}$ & 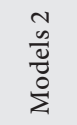 & $\begin{array}{l}m \\
\frac{n}{2} \\
\frac{0}{0} \\
\dot{\Sigma}\end{array}$ & $\begin{array}{l}\vec{y} \\
\frac{n}{d} \\
\frac{\tilde{g}}{2}\end{array}$ & 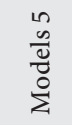 & 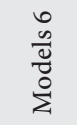 \\
\hline$L_{W}(\mathrm{~m})$ & 0.42 & 0.62 & 0.82 & 1.02 & 1.22 & 1.42 \\
\hline$L_{C B}(\mathrm{~m})$ & 0.942 & 0.946 & 0.950 & 0.954 & 0.958 & 0.962 \\
\hline
\end{tabular}
nose of the models is also listed in Table 2. In Model 1 and Model 2, the wings are in front of the buoyancy centre. In Model 3, the leading edge of the wing root is in front of the buoyancy centre, but the trailing edge of the wing root is after the buoyancy centre. In Model 4, Model 5 and Model 6, the wings are behind the buoyancy centre. The parameters of Model 4 are shown in Table 3.

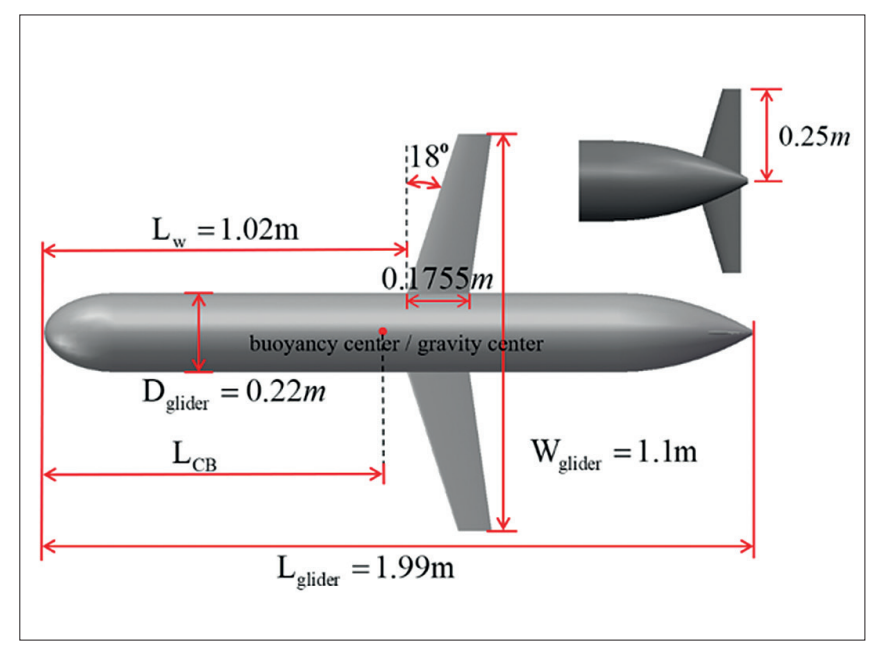

Fig. 3. Some geometric dimensions of gliders (the wing position of Model 4)

Tab. 2. Wing position in glider models 
Tab. 3. Parameters of Model 4

\begin{tabular}{|c|c|}
\hline Fixed structure mass $m_{h}$ & $58.92 \mathrm{~kg}$ \\
\hline $\begin{array}{l}\text { Position of the fixed } \\
\text { structure } r_{h}\end{array}$ & {$\left[\begin{array}{lll}-0.075 & 0 & 0.0033\end{array}\right] \mathrm{m}$} \\
\hline $\begin{array}{l}\text { Inertia of the fixed } \\
\text { structure } I_{h}\end{array}$ & $\operatorname{diag}\left(\left[\begin{array}{llll}0.59 & 15.14 & 15.4\end{array}\right]\right) \mathrm{kg} \cdot \mathrm{m}^{2}$ \\
\hline Movable block mass $m_{p}$ & $11 \mathrm{~kg}$ \\
\hline $\begin{array}{l}\text { Position of the movable } \\
\text { block } r_{p}\end{array}$ & $\begin{array}{c}\boldsymbol{R}_{p}=0.014 \mathrm{~m} ; 0.3516 \mathrm{~m}<r_{p x}<0.4516 \mathrm{~m} \\
-90 \mathrm{deg}<\gamma<90 \mathrm{deg}\end{array}$ \\
\hline $\begin{array}{l}\text { Inertia of the movable } \\
\text { block } I_{p}^{0}\end{array}$ & $\operatorname{diag}\left(\left[\begin{array}{llll}0.02 & 1.82 & 1.82\end{array}\right]\right) \mathrm{kg} \cdot \mathrm{m}^{2}$ \\
\hline Net buoyancy mass $m_{b}$ & $-0.5 \mathrm{~kg}<m_{b}<0.5 \mathrm{~kg}$ \\
\hline $\begin{array}{l}\text { Position of the net } \\
\text { buoyancy } r_{b}\end{array}$ & {$\left[\begin{array}{lll}0 & 0 & 0\end{array}\right] \mathrm{m}$} \\
\hline Displaced fluid mass $m$ & $59.92 \mathrm{~kg}$ \\
\hline
\end{tabular}

\section{ADDED MASS, ADDED INERTIA, AND COUPLING TERMS}

In this paper, inertial hydrodynamic components are expressed by the added mass, added inertia, and coupling terms [25]. Since the glider has two symmetry planes $(O-X Y$ and $O-X Z$ ), the added mass $\boldsymbol{M}_{f}$ and added inertia matrix $\boldsymbol{J}_{f}$ are approximately diagonal and have the form:

$$
\boldsymbol{M}_{f}=\left[\begin{array}{ccc}
X_{\dot{u}} & 0 & 0 \\
0 & Y_{\dot{v}} & 0 \\
0 & 0 & Z_{\dot{w}}
\end{array}\right], \boldsymbol{J}_{f}=\left[\begin{array}{ccc}
K_{\dot{p}} & 0 & 0 \\
0 & M_{\dot{q}} & 0 \\
0 & 0 & N_{\dot{r}}
\end{array}\right]
$$

$X_{\dot{w}}, Y_{\dot{v}}$ and $Z_{\dot{w}}$ are the acceleration fluid mass terms generated from the force along the $O-X, O-Y$ and $O-Z$ axes, respectively. $K_{\dot{p}}, M_{\dot{q}}$ and $N_{\dot{r}}$ are the acceleration fluid inertia terms generated from the moments around the $O-X, O-Y$ and $O-Z$ axes, respectively.

Because of the symmetry of the glider, the coupling term $C_{f}$ has the form:

$$
C_{f}=\left[\begin{array}{ccc}
0 & 0 & 0 \\
0 & 0 & M_{\dot{w}} \\
0 & N_{\dot{v}} & 0
\end{array}\right]
$$

where $M_{\dot{w}}$ is the pitch moment with respect to the acceleration in the $O-Z$ axis and $N_{\dot{v}}$ is the yaw moment with respect to the acceleration in the $O-Y$ axis.

The added hydrodynamic terms for each model are computed by potential flow theory and the results are shown in Table. 4 [26]. The results show that the added mass of the six models are similar. The wing position mainly affects the moment around the $O-Y$ axis and its related parameters, such as $M_{\dot{q}}$ and $M_{\dot{w}}$.

\section{VISCOUS HYDRODYNAMIC COEFFICIENTS}

In the flow frame, the components of the hydrodynamic force $\boldsymbol{F}_{\boldsymbol{h}}=[-\boldsymbol{D} \boldsymbol{S} \boldsymbol{F}-\boldsymbol{L}]^{T}$ and the hydrodynamic moment $\boldsymbol{T}_{\boldsymbol{h}}=\left[\begin{array}{lll}\boldsymbol{T}_{D L 1} & \boldsymbol{T}_{D L 2} & \boldsymbol{T}_{D L 3}\end{array}\right]^{T}$ are usually modelled as [22]:

$$
\begin{aligned}
& D=\left(K_{D 0}+K_{D} \alpha^{2}\right) V^{2} \\
& S F=K_{\beta} \beta V^{2} \\
& L=\left(K_{L 0}+K_{L} \alpha\right) V^{2} \\
& T_{D L 1}=\left(K_{M R} \beta+K_{p} \mathrm{p}\right) V^{2} \\
& T_{D L 2}=\left(K_{M 0}+K_{M} \alpha+K_{q} \mathrm{q}\right) V^{2} \\
& T_{D L 3}=\left(K_{M Y} \beta+K_{r} \mathrm{r}\right) V^{2}
\end{aligned}
$$

The rotation matrix is then used to map the hydrodynamic force and moment from the flow frame to the body frame:

$$
\begin{gathered}
F=R_{B C} F_{h} \\
T=R_{B C} T_{h}
\end{gathered}
$$

$\boldsymbol{R}_{B C}$ is expressed in the form:

$$
\boldsymbol{R}_{B C}=\left[\begin{array}{ccc}
c \alpha c \beta & -c \alpha s \beta & -s \alpha \\
s \beta & c \beta & 0 \\
s \alpha c \beta & -s \alpha s \beta & c \alpha
\end{array}\right]
$$

The commercial CFD software STAR-CCM+ is based on the incompressible Reynolds Averaged Navier Stokes equation and is used to compute the hydrodynamic force and moment in this paper. Because no experimental data of NACA0012 are found, the published experimental results of Zarruk [27] are taken as an example to verify the accuracy of the CFD calculation. The standard NACA0009 aerofoil used in this experiment has a chord length of $0.12 \mathrm{~m}$ at the root, $0.06 \mathrm{~m}$ at the tip and $0.30 \mathrm{~m}$ at the wingspan. As shown in Fig. 4, the lift

Tab. 4. Added hydrodynamic terms

\begin{tabular}{|c|c|c|c|c|c|c|c|c|}
\hline & \multicolumn{4}{|c|}{$M_{f}(\mathrm{~kg})$} & \multicolumn{3}{|c|}{$J_{f}\left(\mathrm{~kg} \cdot \mathrm{m}^{2}\right)$} & \multicolumn{2}{c|}{$C_{f}(\mathrm{~kg} \cdot \mathrm{m})$} \\
\cline { 2 - 9 } & $X_{\dot{u}}$ & $Y_{\dot{\nu}}$ & $Z_{\dot{w}}$ & $K_{\dot{p}}$ & $M_{\dot{q}}$ & $N_{\dot{r}}$ & $N_{\dot{\nu}}$ & $M_{\dot{w}}$ \\
\hline Model 1 & 2.92 & 69.95 & 87.38 & 1.29 & 18.43 & 18.63 & -4.76 & -7.31 \\
\hline Model 2 & 2.91 & 69.90 & 87.51 & 1.29 & 16.10 & 18.69 & -4.34 & -3.69 \\
\hline Model 3 & 2.90 & 69.91 & 87.66 & 1.29 & 15.29 & 18.70 & -3.95 & 0.10 \\
\hline Model 4 & 2.90 & 69.91 & 87.57 & 1.29 & 16.01 & 18.66 & -3.55 & 3.89 \\
\hline Model 5 & 2.91 & 69.93 & 87.43 & 1.29 & 18.27 & 18.57 & -3.15 & 7.58 \\
\hline Model 6 & 2.93 & 69.95 & 86.79 & 1.29 & 21.82 & 18.43 & -2.73 & 10.90 \\
\hline
\end{tabular}




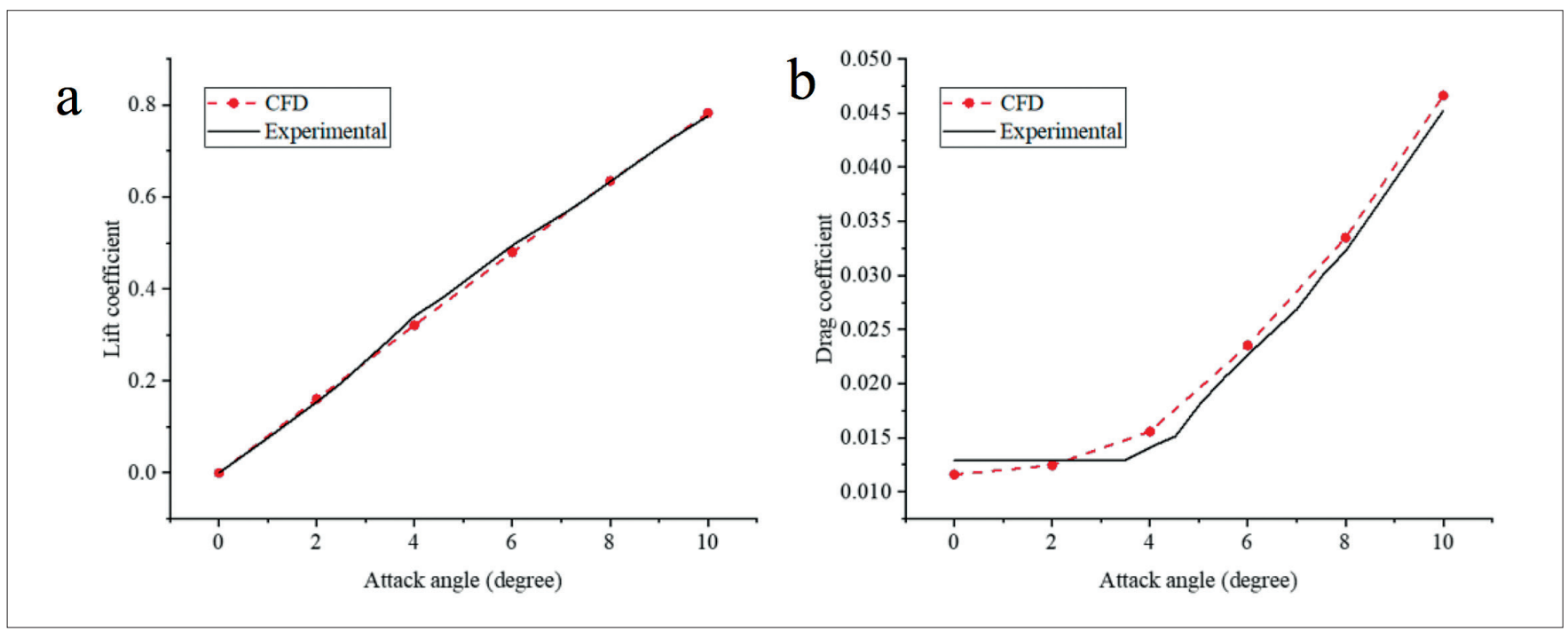

Fig. 4. Comparison of experimental and CFD results. (a) Lift coefficient. (b) Drag coefficient

coefficient and drag coefficient calculated by CFD show good agreement with the experimental results.

As shown in Fig. 5, only half of the domain is meshed as the body is axisymmetric. In this paper, the inlet position is 1.5 times $\mathrm{L}_{\text {glider }}$ away from the glider and the outlet is 3.5 times $\mathrm{L}_{\text {glider }}$ away from the glider. The top, bottom and side boundaries are 9 times $\mathrm{D}_{\text {glider }}$ away from the glider and the assigned velocity inlet condition. The SST (Menter) $k-\omega$ turbulence model is selected to simulate the surrounding flow with a grid point for the first cell at $y^{+}<1[28]$. Based on the grid independence study shown in Fig. 6, the number of the mesh is set to 3.3 million.

The results of the viscous hydrodynamic forces of six models are shown in Fig. 7. Only the positive attack angle is calculated because of the symmetry of the models. The results show that the lift forces, drag forces and lift-drag ratios of the six models are similar but the pitch moments are quite different, which is consistent with the previous conclusions [9]. This may be because the wing-hull interaction is similar at small attack angles, so they have similar lift and drag. However, the arm force is quite different, so the pitch moment is also quite

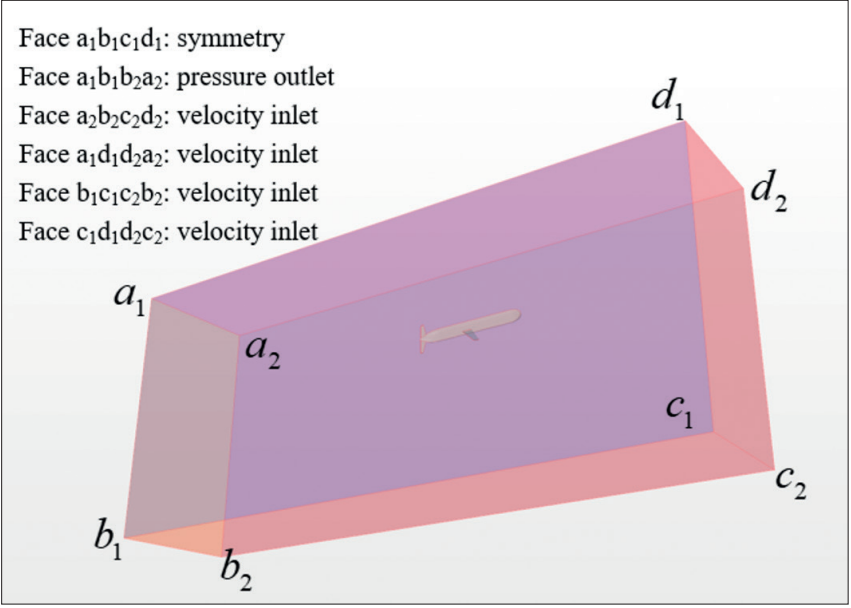

Fig. 5. Domain and boundary conditions

different. Furthermore, the difference of wing position leads to the opposite direction of pitching moment. This will further impression the performance of the underwater glider in motion,

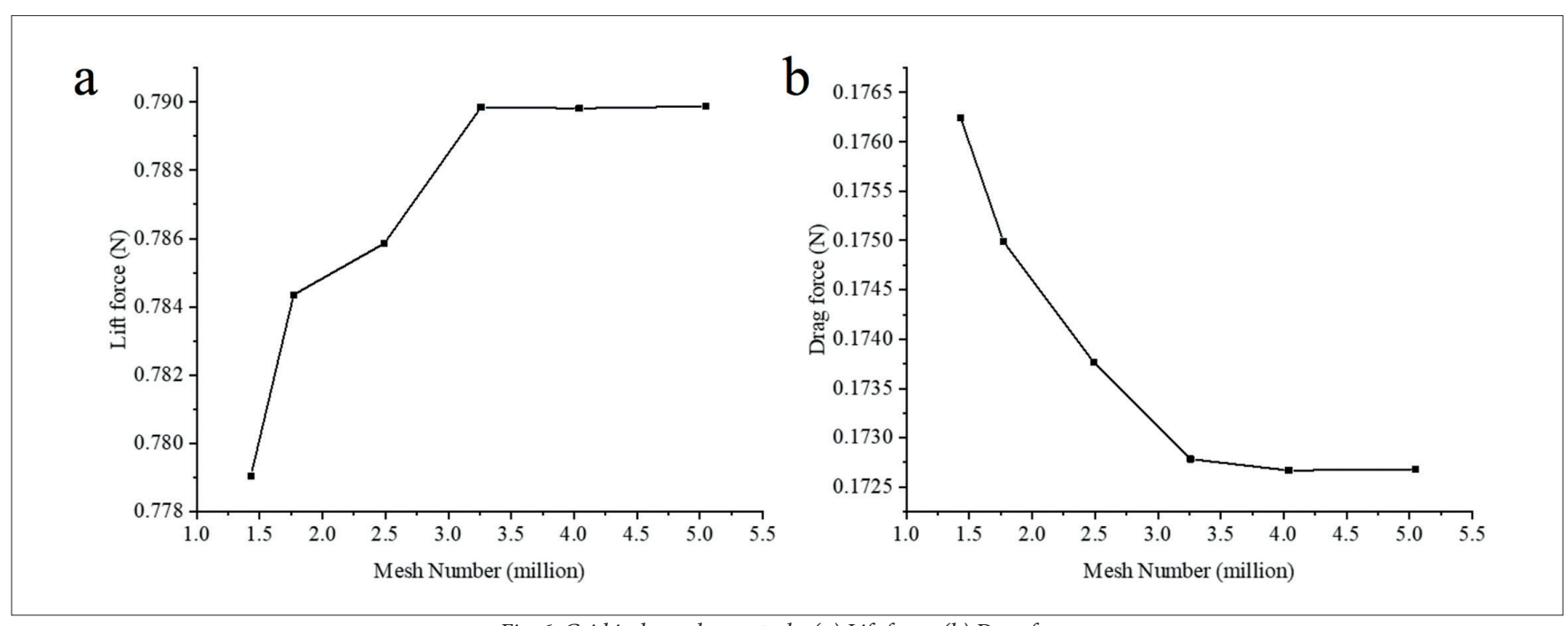

Fig. 6. Grid independency study. (a) Lift force. (b) Drag force 
a
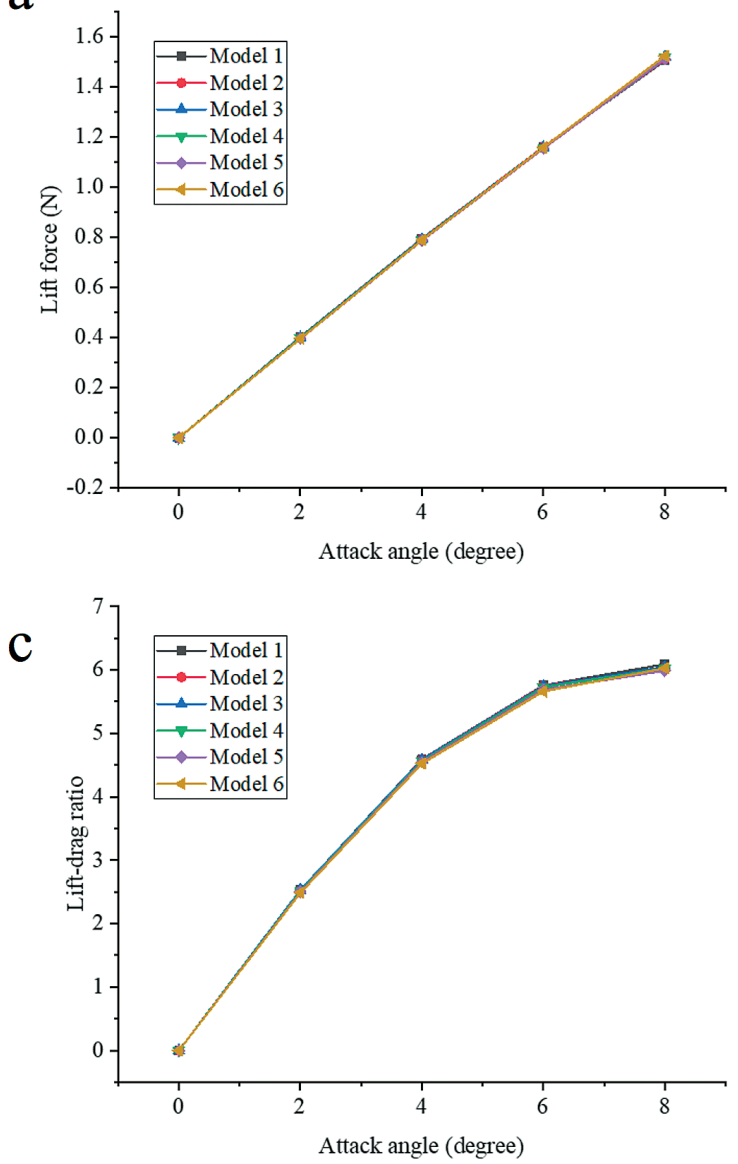

b
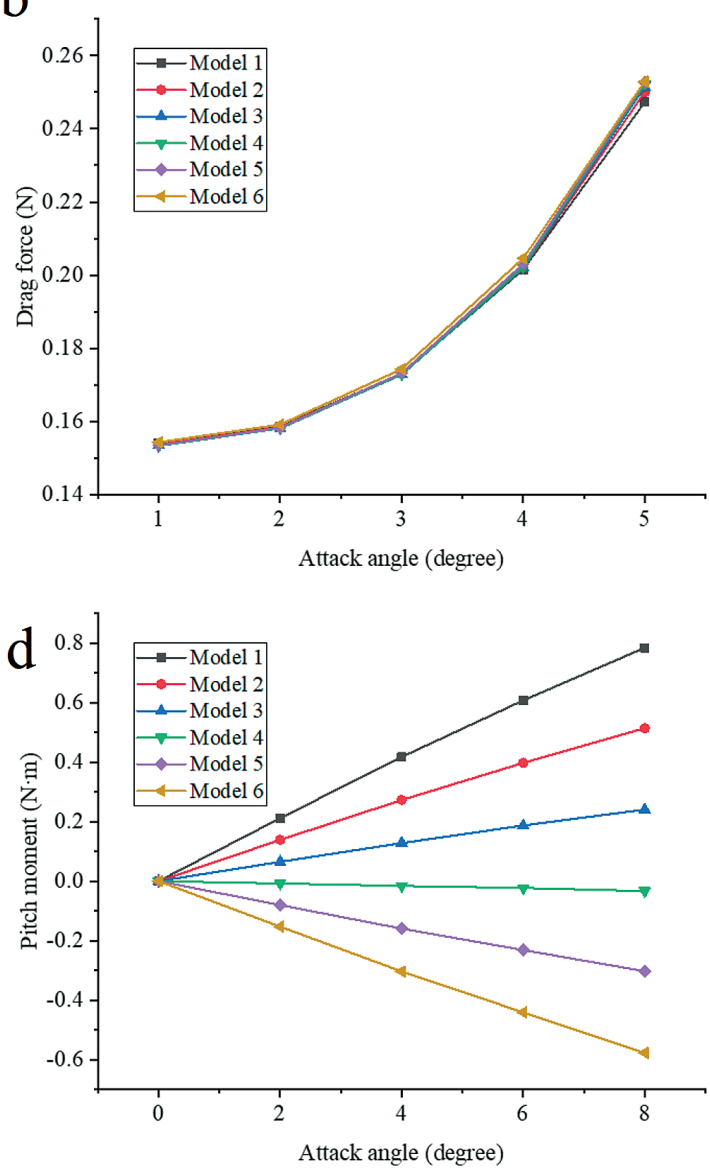

Fig. 7. Variation of hydrodynamic forces with attack angle. (a) Lift force. (b) Drag force. (c) Lift-drag ratio. (d) Pitch moment

By entering the results into Eq. (22), we get the viscous hydrodynamic coefficients of the models, as shown in Table 5. They have similar lift coefficients and drag coefficients but quite different pitch moment coefficients.

\section{MOTION SIMULATION AND DISCUSSION}

\section{VALIDATION OF THE MOTION SIMULATION}

In this paper, the published results in [22] are compared to validate the results of motion simulation. All the parameters needed for motion simulation are listed in Table 6. And in the motion simulation, the influence of dynamic pressure on buoyancy centre and the change of gravity centre caused by the change of $m_{b}$ are ignored. Because the offset is very small, it almost does not affect the results.

When the control parameters $\left[m_{b}, r_{p x}, \gamma\right]$ are set as $[0.3 \mathrm{~kg}$, $0.4216 \mathrm{~m}, 45^{\circ}$ ], the downward spiral motion is simulated based on the dynamic model in this paper and shown in Fig. 8. When the control parameters $\left[m_{b}, r_{p x}\right]$ are set as $[0.3 \mathrm{~kg}, 0.4216 \mathrm{~m}]$ and $\gamma$ varies from $30^{\circ}$ to $60^{\circ}$, the change of glider turning radius with the moveable block position and the comparison with the results in [22] are shown in Fig. 9. There is little difference due to the introduction of some simplifications in [22]. In general, the dynamic model in this paper is proved to be reasonable and feasible.

Tab. 5. The viscous hydrodynamic coefficients

\begin{tabular}{|c|c|c|c|c|c|c|}
\hline & $\boldsymbol{K}_{\boldsymbol{D} 0}(\mathrm{~kg} / \mathrm{m})$ & $\boldsymbol{K}_{\boldsymbol{D}}(\mathrm{kg} / \mathrm{m} / \mathrm{rad})$ & $\boldsymbol{K}_{L 0}(\mathrm{~kg} / \mathrm{m})$ & $\boldsymbol{K}_{L}(\mathrm{~kg} / \mathrm{m} / \mathrm{rad})$ & $\boldsymbol{K}_{M 0}(\mathrm{~kg} / \mathrm{m})$ & $\boldsymbol{K}_{M}(\mathrm{~kg} / \mathrm{rad})$ \\
\hline Model 1 & 4.85 & 153.65 & 0 & 351.17 & 0 & 183.44 \\
\hline Model 2 & 4.82 & 159.39 & 0 & 351.78 & 0 & 120.21 \\
\hline Model 3 & 4.80 & 161.55 & 0 & 352.85 & 0 & 56.41 \\
\hline Model 4 & 4.80 & 163.15 & 0 & 352.27 & 0 & -7.36 \\
\hline Model 5 & 4.81 & 164.57 & 0 & 350.89 & 0 & -70.53 \\
\hline Model 6 & 4.84 & 163.94 & 0 & 352.76 & 0 & -134.21 \\
\hline
\end{tabular}


Tab. 6. Parameters of Seawing in [22]

\begin{tabular}{|c|c|}
\hline Fixed structure mass $m_{h}$ & $54.28 \mathrm{~kg}$ \\
\hline $\begin{array}{l}\text { Position of the fixed } \\
\text { structure } r_{h}\end{array}$ & {$\left[\begin{array}{lll}-0.0814 & 0 & 0.0032\end{array}\right] \mathrm{m}$} \\
\hline $\begin{array}{l}\text { Inertia of the fixed } \\
\text { structure } I_{h}\end{array}$ & $\operatorname{diag}\left(\left[\begin{array}{llll}0.60 & 15.27 & 15.32\end{array}\right]\right) \mathrm{kg} \cdot \mathrm{m}^{2}$ \\
\hline Movable block mass $m_{p}$ & $11 \mathrm{~kg}$ \\
\hline $\begin{array}{l}\text { Position of the movable } \\
\text { block } r_{p}\end{array}$ & $\begin{array}{c}\boldsymbol{R}_{p}=0.014 \mathrm{~m} ; 0.3516 \mathrm{~m}<r_{p x}<0.4516 \mathrm{~m} \\
-90 \mathrm{deg}<\gamma<90 \mathrm{deg}\end{array}$ \\
\hline $\begin{array}{l}\text { Inertia of the movable } \\
\text { block } I_{p}^{0}\end{array}$ & $\operatorname{diag}\left(\left[\begin{array}{llll}0.02 & 10.16 & 0.17\end{array}\right]\right) \mathrm{kg} \cdot \mathrm{m}^{2}$ \\
\hline Net buoyancy mass $m_{b}$ & $-0.5 \mathrm{~kg}<m_{b}<0.5 \mathrm{~kg}$ \\
\hline $\begin{array}{l}\text { Position of the net } \\
\text { buoyancy } r_{b}\end{array}$ & {$\left[\begin{array}{lll}0 & 0 & 0\end{array}\right] \mathrm{m}$} \\
\hline Added mass $\boldsymbol{M}_{f}$ & $\operatorname{diag}([1.4849 .5865 .92]) \mathrm{kg}$ \\
\hline Added inertia matrix $\boldsymbol{J}_{f}$ & $\operatorname{diag}([0.537 .8810 .18]) \mathrm{kg} \cdot \mathrm{m}^{2}$ \\
\hline Added coupling terms $C_{f}$ & $N_{\dot{v}}=2.57 \mathrm{~kg} \cdot \mathrm{m}, M_{\dot{w}}=3.61 \mathrm{~kg} \cdot \mathrm{m}$ \\
\hline Coefficients of drag force $D$ & $K_{D 0}=7.19 \mathrm{~kg} / \mathrm{m}, \boldsymbol{K}_{D}=386.29 \mathrm{~kg} / \mathrm{m} / \mathrm{rad}^{2}$ \\
\hline Coefficients of side force $S F$ & $\boldsymbol{K}_{\beta}=-115.65 \mathrm{~kg} / \mathrm{m} / \mathrm{rad}$ \\
\hline Coefficients of lift force $L$ & $\boldsymbol{K}_{L 0}=-0.36 \mathrm{~kg} / \mathrm{m}, \boldsymbol{K}_{L}=440.99 \mathrm{~kg} / \mathrm{m} / \mathrm{rad}$ \\
\hline Coefficients of $T_{D L 1}$ & $K_{M R}=-58.27 \mathrm{~kg} / \mathrm{rad}, K_{M}=-19.83 \mathrm{~kg} \cdot \mathrm{s} / \mathrm{rad}$ \\
\hline Coefficients of $T_{D L 2}$ & $\begin{array}{c}K_{M 0}=0.28 \mathrm{~kg}, K_{M}=-65.84 \mathrm{~kg} / \mathrm{rad}, \\
K_{q}=-205.64 \mathrm{~kg} \cdot \mathrm{s} / \mathrm{rad}^{2}\end{array}$ \\
\hline Coefficients of $T_{D L 3}$ & $\begin{array}{c}K_{M Y}=34.10 \mathrm{~kg} / \mathrm{rad} \\
K_{r}=-389.30 \mathrm{~kg} \cdot \mathrm{s} / \mathrm{rad}^{2}\end{array}$ \\
\hline
\end{tabular}

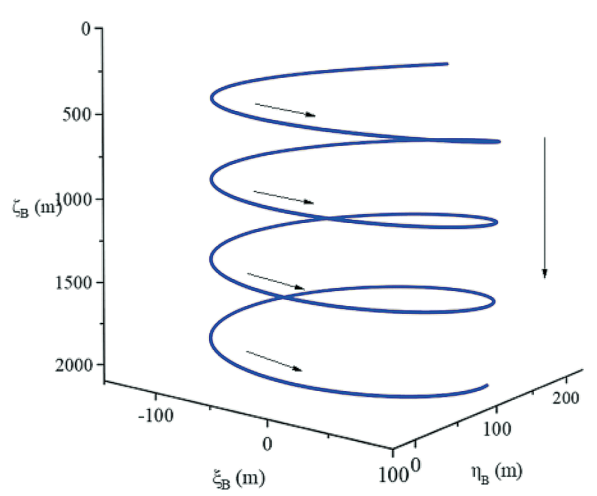

Fig. 8. Downward spiral motion

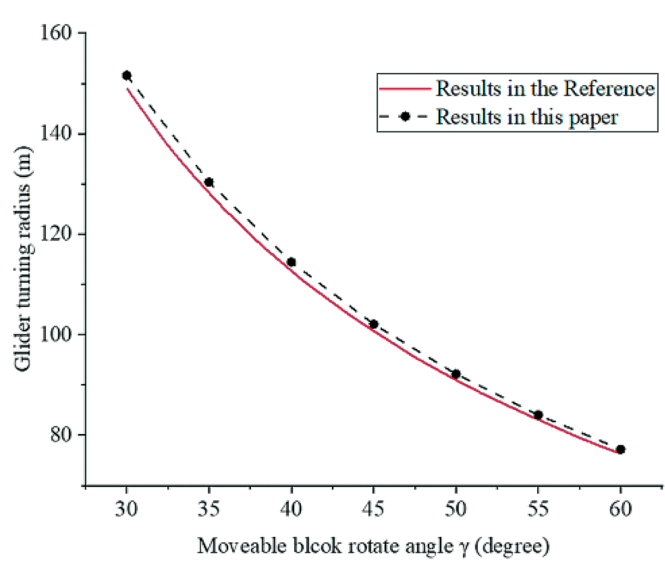

Fig. 9. Validation of the motion simulation

\section{MOTION OF STEADY GLIDING}

In this section, the influence of the wing position on the motion of steady gliding is studied. Gliding speed and gliding angle were calculated with different positions of the movable block. The net buoyancy $m_{b}$ is set to $0.5 \mathrm{~kg}$ during the descent process and $-0.5 \mathrm{~kg}$ during the ascent process. The movable block is limited to only moving along the $O-X$ axis and not rotating around the $O-X$ axis, which means that $\gamma$ is equal to zero. Because of the calculation of viscous hydrodynamic forces, only the data with and attack angle between -8 degrees and 8 degrees are retained. The simulation results are shown in Fig. 10.

The results show that, for a given net buoyancy, gliders with different wing position have the same gliding velocity and the same attack angle at the same gliding angle. Model 1, which has the minimum wing position parameter $L_{W}$, needed to move the movable block further to get the same gliding angle as the other models. This is because, at the same gliding angle, Model 1 has a larger overturning moment due to the forward position of the wing. As a result, it needs to move the movable block further to balance the pitch moment during equilibrium gliding. Model 6, which has the maximum wing position parameter $L_{W}$, can achieve the greatest gliding angle with the greatest gliding speed. When the movable block moves in the same range, the model with wings in the rear can realise a larger gliding angle than the model with wings in the front. Therefore, the range of glider motion attitude can be increased by moving the wing position backward, especially when the movable block has limited room to move. In addition, it should be noted that Model 6 needs to move the movable block back to have a smaller gliding angle during its dive.

\section{MOTION AFTER RECEIVING A SMALL DISTURBANCE}

Vehicle geometry affects stability as well as performance. Fan [29] studied the effect of the wing position on stability by frequency analysis. In this paper, the influence of wing position on the longitudinal stability of an underwater glider is studied as a time-domain response. In this way, it can intuitively show the motion state of an underwater glider after receiving disturbance.

Previous analysis shows that three models can show the effect of wing position on the dynamic motion characteristics of an underwater glider. Therefore, in this section, Model 2, Model 4 and Model 6 are selected to study the influence of wing position on the motion of an underwater glider after receiving a small disturbance. In Model 2, the wings are in front of the buoyancy centre. In Model 4 and Model 6, the wings are behind the buoyancy centre. It is assumed that the underwater glider receives a small environmental disturbance during steady gliding. In the motion simulation analysis, the small disturbance is reflected by the suddenly changed attitude angle. To simulate the change process of attitude angle, the rotational hydrodynamic coefficient $K_{q}$ in the vertical plane is calculated by the method described in [22]. The results are shown in Table 7. 


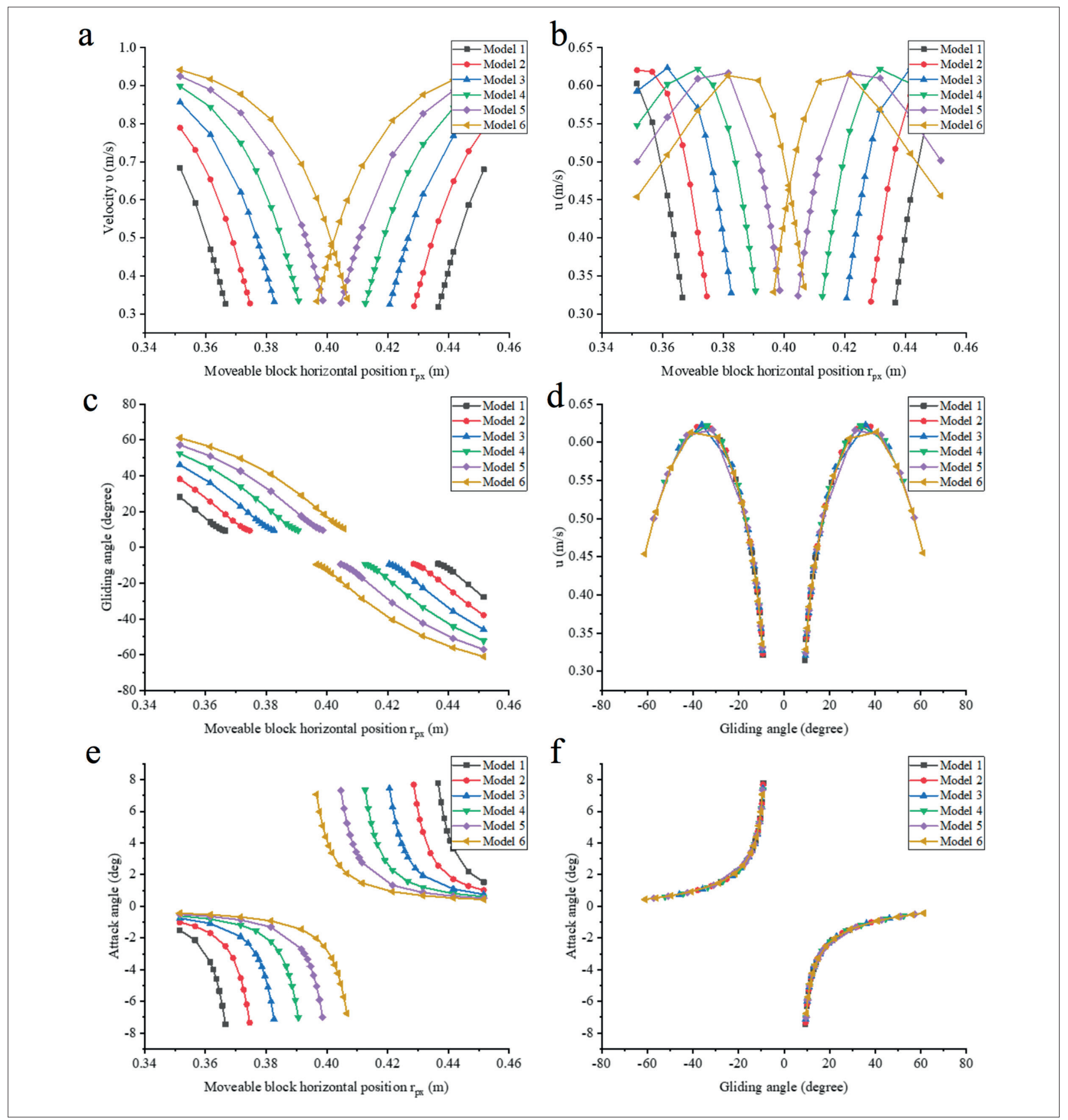

Fig. 10. Motion simulation results. (a) Velocity $v$ vs $r p x$. (b) Horizontal velocity u vs rpx. (c) Gliding angle vs rpx.

(d) Relationship between horizontal velocity $u$ and gliding angle. (e) Attack angle vs $r p x$. (f) Relationship between attack angle and gliding angle

Tab. 7. Rotational hydrodynamic coefficient $\boldsymbol{K}_{q}$

\begin{tabular}{|l|l|l|l|}
\hline & Model 2 & Model 4 & Model 6 \\
\hline$K_{q}\left(\mathrm{~kg} \cdot \mathrm{s} / \mathrm{rad}^{2}\right)$ & -220.02 & -49.92 & -250.88 \\
\hline
\end{tabular}

The initial state of the motion simulation is set as steady gliding at a gliding angle of about $-35^{\circ}$. At the 5 th second, the underwater glider receives environmental disturbance and produces a deflection angle of $-5^{\circ}$. As a result, the gliding angle of the underwater glider changes to $-40^{\circ}$. The net buoyancy is set as $0.5 \mathrm{~kg}$ and the moveable block remains constant throughout the simulation. The results are shown in Fig. 11.

The results show that all three models can return to the initial state, whether the wing is in front of or behind the buoyancy centre. Model 4 has a larger angular velocity and can recover to the equilibrium state faster but it oscillates slightly, around the steady state. Model 2 and Model 6 have smaller angular velocities and take longer to recover to their initial 
a

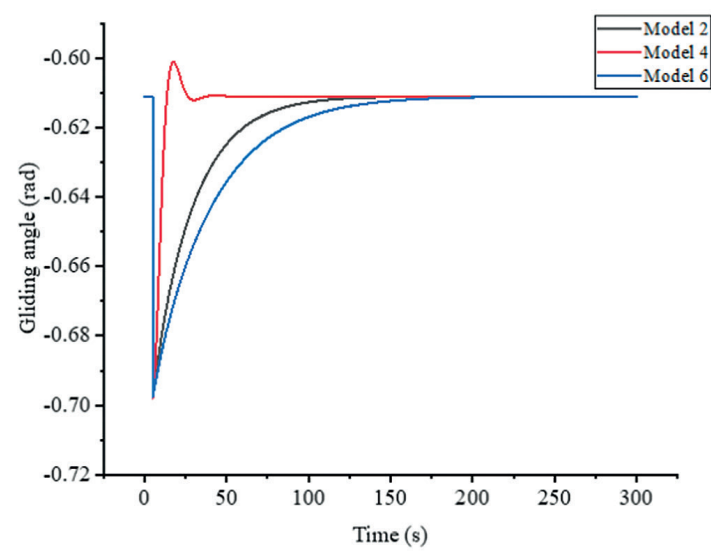

c

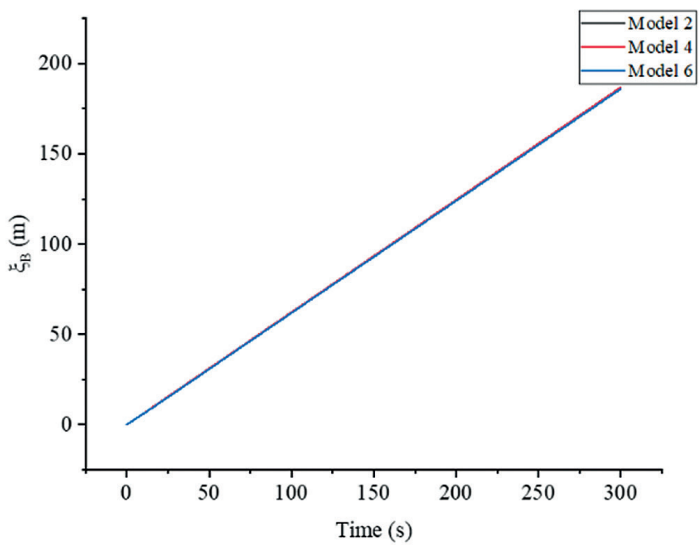

e

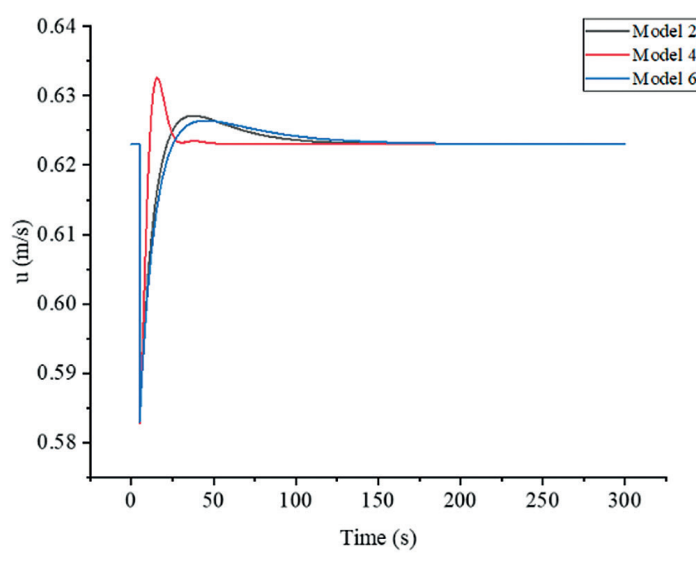

g

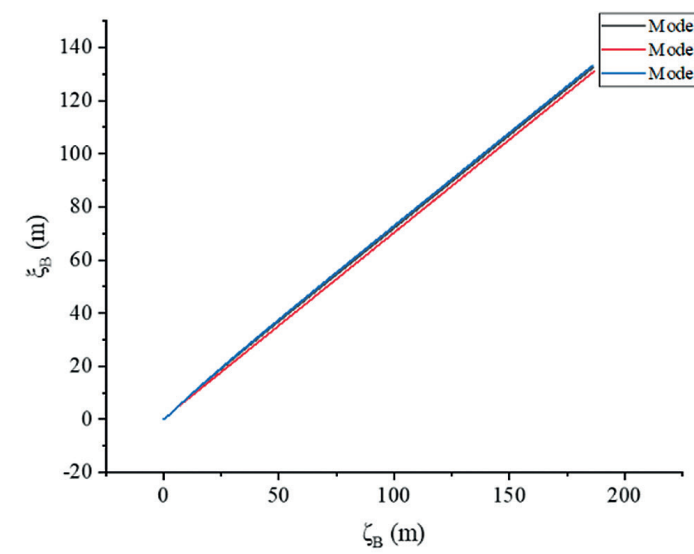

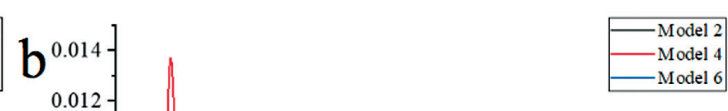

Do.012.
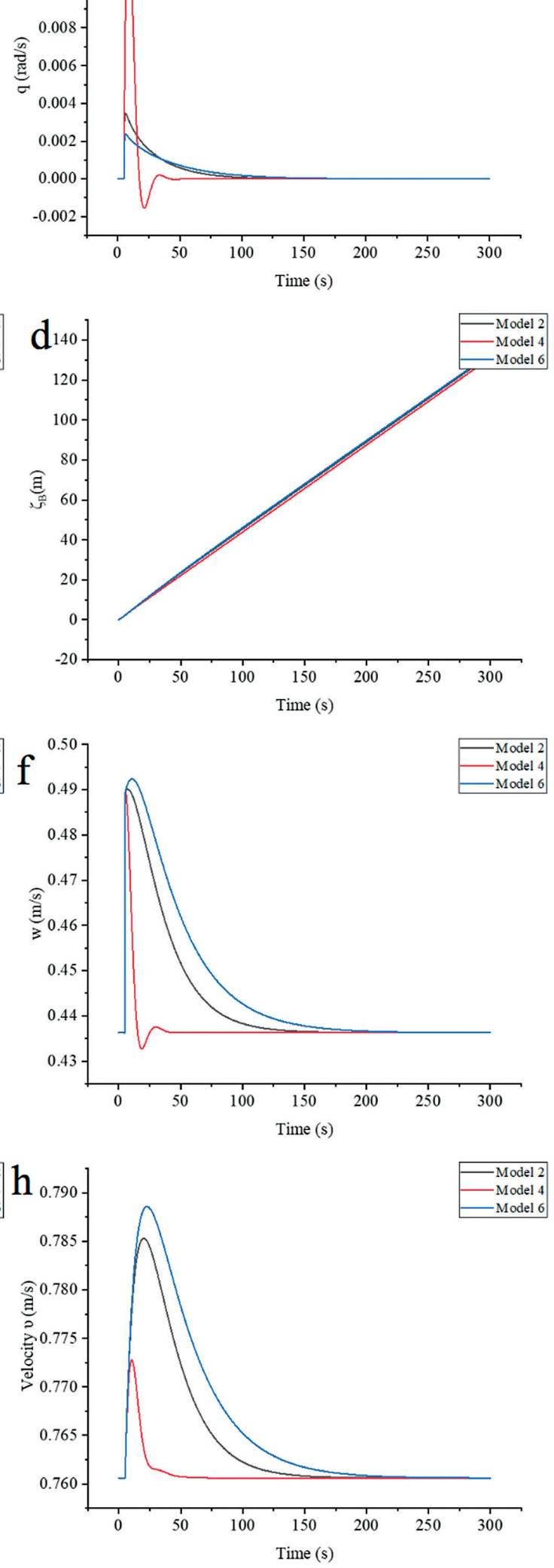

Fig. 11. Motion states of the glider after disturbance. (a) Gliding angle vs Time. (b) Angle velocity $q$ vs Time. (c) Horizontal position $\xi_{B} v s$ Time. (d) Vertical position $\zeta_{B} v$ s Time. (e) Horizontal velocity $u$ vs Time. (f) Vertical velocity $w$ vs Time. (g) Simulated trajectory. (h) Velocity $v$ vs Time 

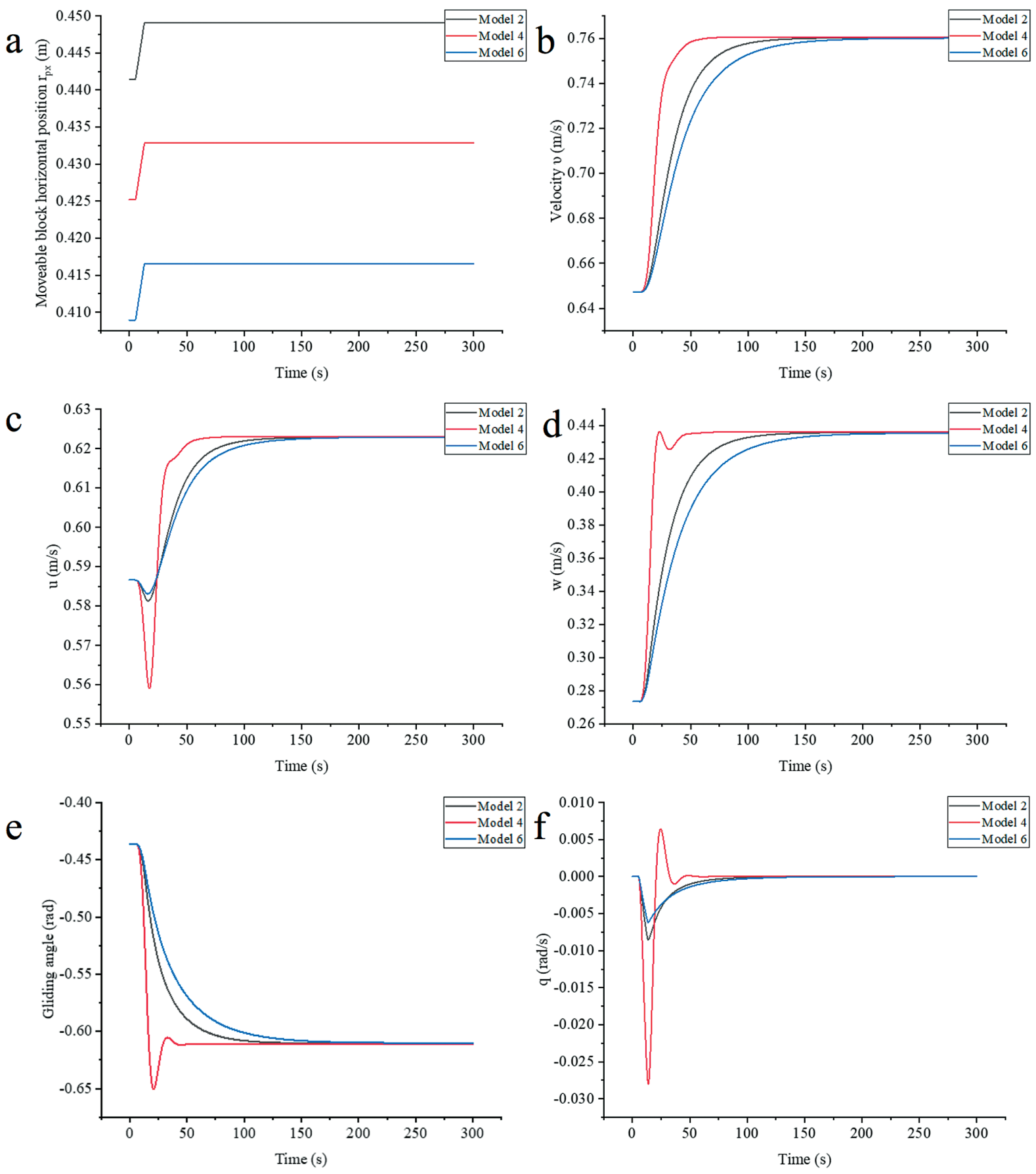

Fig. 12. Motion states of the glider after adjusting gliding angle. (a) Moveable block horizontal position rpx vs Time.

(b) Velocity $v$ vs Time. (c) Horizontal velocity $u$ vs Time. (d) Vertical velocity $w$ vs Time. (e) Gliding angle vs Time. (f) Angle velocity $q$ vs Time

state. The reason for this difference is that the wings of Model 2 and Model 6 are far away from the buoyancy centre, which makes Model 2 and Model 6 have greater pitch moments in the process of rotation. Because Model 4 returns to the initial state faster, its trajectory deviation is smaller. In addition, the velocity of Model 6 changes the most and horizontal velocity approaches the stable value faster than vertical velocity. This means that if we want the glider to have a smaller trajectory offset after being disturbed, the wings should be installed near the buoyancy centre. If we want the glider to have a more stable attitude after being disturbed, we should install the wing away from the buoyancy centre.

\section{MOTION AFTER ADJUSTING GLIDING ANGLE}

In this section, Model 2, Model 4 and Model 6 are selected to study the influence of wing position on the motion after adjusting the gliding angle of an underwater glider. The initial 
state of the motion simulation is set as the steady gliding of the underwater glider at a gliding angle of $-25^{\circ}$. At the 5 th second, the moveable block is moved to adjust the gliding angle. The target gliding angle is $-35^{\circ}$. The net buoyancy is set as $0.5 \mathrm{~kg}$ throughout the simulation. The change in the position of the movable block with time and the simulation results are shown in Fig. 12.

The results show that all three models need to move the moveable block the same distance to produce the same change of gliding angle. Model 4 has a larger angular velocity and can recover to its equilibrium state faster. The change of the gliding angle of Model 6 is more stable and it hardly vibrates near the target angle. This means that if we want the glider to respond faster to attitude adjustment, the wings should be installed near the buoyancy centre. If we want to have a higher stability, we should install the wing away from the buoyancy centre.

\section{CONCLUSIONS}

In this paper, the effect of wing position on the dynamic motion characteristics of an underwater glider is analysed by motion simulation. These results could be helpful when choosing wing position, according to different performance requirements, when designing an underwater glider. By studying the motion of steady gliding, the motion after receiving a small disturbance, and the motion after adjusting the gliding angle of underwater gliders with different wing positions, we arrive at the following conclusions:

1. The wing position of the underwater glider has a great influence on the gliding angle but does not affect the relationship between gliding angle and gliding speed. The range of the gliding angle of the glider can be increased by moving the wing position backward when the adjustment ability of the movable block is limited.

2. The closer the wing position is to the buoyancy centre, the faster it can recover to its previous state after receiving a disturbance, and the smaller the trajectory deviation is.

3. The farther the wing position is from the buoyancy centre, the slower the state of change of the underwater glider. This can reduce drastic changes in underwater glider attitude.

The results presented here are based on numerical studies and should be validated by prototype experiments in the laboratory and the field.

\section{ACKNOWLEDGEMENTS}

This work was supported by the Natural Science Foundation of Liaoning Province in 2020 (Grant No. 2020-MS-125); the State Key Laboratory of Ocean Engineering, Shanghai Jiao Tong University (Grant No. 1904); the Fundamental Research Funds for the Central Universities (Grant No. 3132021120); and the National Key Research and Development Program of China (Grant No. 2016YFC0301500).

\section{REFERENCES}

1. H. Stommel, “The Slocum Mission”, Oceanography. 1989. Vol. 2(1), 22-25, doi: 10.5670/oceanog.1989.26.

2. D.C. Webb, P.J. Simonetti, and C.P. Jones, "SLOCUM: An underwater glider propelled by environmental energy", IEEE Journal of Oceanic Engineering. 2001. Vol. 26(4), 447-452, doi: $10.1109 / 48.972077$.

3. J. Sherman, R.E. Davis, W.B. Owens, et al., "The autonomous underwater glider "spray"”, IEEE Journal of Oceanic Engineering. 2001. Vol. 26(4), 437-446, doi: 10.1109/48.972076.

4. C.C. Eriksen, T.J. Osse, R.D. Light, et al., "Seaglider: A longrange autonomous underwater vehicle for oceanographic research", IEEE Journal of Oceanic Engineering. 2001. Vol. 26(4), 424-436, doi: 10.1109/48.972073.

5. S. Wang, X. Sun, Y. Wang, et al., "Dynamic Modeling and Motion Simulation for A Winged Hybrid-Driven Underwater Glider", China Ocean Engineering. 2011. Vol. 25(1), 97-112, doi: 10.1007/s13344-011-0008-7.

6. J. Yu, A. Zhang, W. Jin, et al., "Development and experiments of the Sea-Wing underwater glider", China Ocean Engineering. 2011. Vol. 25(4), 721-736, doi: 10.1007/s13344-011-0058-x.

7. D.L. Rudnick, R.E. Davis, C.C. Eriksen, et al., "Underwater Gliders for Ocean Research", Marine Technology Society Journal. 2004. Vol. 38(2), 73-84, doi: $10.4031 / 002533204787522703$.

8. R.V.S. Shankar and R. Vijayakumar, "Numerical Study of the Effect of Wing Position on Autonomous Underwater Glider", Defence Science Journal. 2020. Vol. 70(2), 214-220, doi: $10.14429 /$ dsj.70.14742.

9. M.Y. Javaid, M. Ovinis, F.B.M. Hashim, et al., "Effect of wing form on the hydrodynamic characteristics and dynamic stability of an underwater glider", International Journal of Naval Architecture and Ocean Engineering. 2017. Vol. 9(4), 382-389, doi: 10.1016/j.ijnaoe.2016.09.010.

10. M.Y. Javaid, M. Ovinis, N. Thirumalaiswamy, et al., "Dynamic Motion Analysis of a Newly Developed Autonomous Underwater Glider with Rectangular and Tapered Wing", Indian Journal of Geo-Marine Sciences. 2015. Vol. 44(12), 1928-1936.

11. F. Zhang, J. Thon, C. Thon, et al., "Miniature Underwater Glider: Design and Experimental Results", IEEE-Asme Transactions on Mechatronics. 2014. Vol. 19(1), 394-399, doi: 10.1109/tmech.2013.2279033. 
12. F. Liu, Y. Wang, W. Niu, et al., "Hydrodynamic Performance Analysis and Experiments of A Hybrid Underwater Glider with Different Layout of Wings". OCEANS 2014 - TAIPEI, 2014, doi: 10.1109/OCEANS-TAIPEI.2014.6964512.

13. S. Fan and C. Woolsey, "Elements of Underwater Glider Performance and Stability", Marine Technology Society Journal. 2013. Vol. 47(3), 81-98, doi: 10.4031/mtsj.47.3.4.

14. J.G. Graver and N.E. Leonard, "Underwater glider dynamics and control". 12th international symposium on unmanned untethered submersible technology, 2001.

15. P. Bhatta and N.E. Leonard, "Stabilization and coordination of underwater gliders". Proceedings of the 41st IEEE Conference on Decision and Control, 2002, 2002, doi: 10.1109/CDC.2002.1184836.

16. N.E. Leonard and J.G. Graver, "Model-based feedback control of autonomous underwater gliders", IEEE Journal of Oceanic Engineering. 2001. Vol. 26(4), 633-645, doi: $10.1109 / 48.972106$

17. P. Bhatta and N.E. Leonard, "Nonlinear gliding stability and control for vehicles with hydrodynamic forcing", Automatica. 2008. Vol. 44(5), 1240-1250, doi: 10.1016/j. automatica.2007.10.006.

18. K. Isa and M. Rizal Arshad, "Motion simulation for propeller-driven USM underwater glider with controllable wings and rudder". 2011 2nd International Conference on Instrumentation Control and Automation, 2011.

19. K. Isa and M.R. Arshad, "Dynamic modeling and characteristics estimation for USM underwater glider". 2011 IEEE Control and System Graduate Research Colloquium, 2011, doi: 10.1109/ICSGRC.2011.5991821.

20. M.M. Noh, M.R. Arshad, and R.M. Mokhtar, "Modeling of USM underwater glider (USMUG)". International Conference on Electrical, Control and Computer Engineering 2011 (InECCE), 2011

21. S. Fan and C.A. Woolsey, "Dynamics of underwater gliders in currents”, Ocean Engineering. 2014. Vol. 84(JUL.1), 249-258, doi: 10.1016/j.oceaneng.2014.03.024.

22. S. Zhang, J. Yu, A. Zhang, et al., "Spiraling motion of underwater gliders: Modeling, analysis, and experimental results", Ocean Engineering. 2013. Vol. 60, 1-13, doi: 10.1016/j.oceaneng.2012.12.023.

23. H. Zhou, T. Wang, L. Sun, et al., "Disc-type Underwater Glider Modeling and Analysis for Omnidirectional and Steering Motion Characteristics", International Journal of Control Automation and Systems. 2020. Vol. 19(1), 532-547, doi: 10.1007/s12555-019-0432-7.
24. J.G. Graver, "Underwater gliders: dynamics, control and design”. Princeton University, 2005.

25. P. Yu, Y. Zhao, T. Wang, et al., "Steady-state Spiral Motion Simulation and Turning Speed Analysis of an Underwater Glider". 2017 4th International Conference on Information, Cybernetics and Computational Social Systems (ICCSS), 2017, doi: 10.1109/ICCSS.2017.8091442.

26. C.W. Chen and N.M. Yan, "Prediction of Added Mass for an Autonomous Underwater Vehicle Moving Near Sea Bottom Using Panel Method”. 2017 4th International Conference on Information Science and Control Engineering (ICISCE), 2017.

27. G.A. Zarruk, P.A. Brandner, B.W. Pearce, et al., "Experimental study of the steady fluid-structure interaction of flexible hydrofoils", Journal of Fluids and Structures. 2014. Vol. 51, 326-343, doi: 10.1016/j.jfluidstructs.2014.09.009.

28. Y. Singh, S.K. Bhattacharyya, and V.G. Idichandy, "CFD approach to modelling, hydrodynamic analysis and motion characteristics of a laboratory underwater glider with experimental results", Journal of Ocean Engineering and Science. 2017. Vol. 2(2), 90-119, doi: 10.1016/j. joes.2017.03.003.

29. S. Fan, A. Wolek, and C.A. Woolsey, "Stability and performance of underwater gliders”. 2012 Oceans, 2012, doi: 10.1109/OCEANS.2012.6404993. 


\section{CONTACT WITH THE AUTHORS}

Xiangcheng Wu

e-mail:wuxiangcheng@dlmu.edu.cn

Dalian Maritime University

No.1 Ganjingzi District

0086116026 Dalian

China

\section{Pengyao Yu}

e-mail:yupengyao@dlmu.edu.cn

Dalian Maritime University

No.1 Ganjingzi District

0086116026 Dalian

China

\section{Guangzhao Li}

e-mail: liguangzhao@dlmu.edu.cn

Dalian Maritime University

No.1 Ganjingzi District

0086116026 Dalian

China

Fengkun Li

e-mail:fengkun_li@dlmu.edu.cn

Dalian Maritime University

No.1 Ganjingzi District

0086116026 Dalian

China 